\title{
Genotype and phenotype correlation in a cohort of Chinese congenital hypothyroidism patients with DUOX2 mutations
}

\author{
Zhangqian Zheng, Lin Yang, Chengjun Sun, Jing Wu, Feihong Luo, Wenhao Zhou, Wei Lu \\ Department Endocrinology and Inherited Metabolic Diseases, Children's Hospital of Fudan University, Shanghai, China \\ Contributions: (I) Conception and design: F Luo, W Lu; (II) Administrative support: W Zhou; (III) Provision of study materials or patients: Z Zheng; \\ (IV) Collection and assembly of data: Z Zheng, J Wu; (V) Data analysis and interpretation: L Yang, C Sun; (VI) Manuscript writing: All authors; (VII) \\ Final approval of manuscript: All authors. \\ Correspondence to: Wenhao Zhou; Wei Lu. Children's Hospital of Fudan University, 399 Wanyuan Rd., Minhang District, Shanghai 201102, China. \\ Email: zhouwenhao@fudan.edu.cn; wei_lu77@163.com.
}

\begin{abstract}
Background: This study aimed to explore the relationship between the phenotype and genotype of congenital hypothyroidism (CH) caused by dual oxidase 2 (DUOX2) mutation in Chinese children, and to investigate the genetic causes of permanent and transient hypothyroidism through next-generation genetic testing technology and long-term clinical follow-up data.

Methods: We recruited 61 patients with thyroid stimulating hormone (TSH) levels of $>10 \mathrm{mIU} / \mathrm{mL}$ during newborn screening, clinical diagnosis of $\mathrm{CH}$, and L-thyroxine (L-T4) oral treatment within 1 month of birth; they were followed up until the present. All CH infants and their parents were genotyped using wholeexome sequencing (WES); DUOX2 variants were detected in 20 infants, and the longitudinal prognosis, genotype, and phenotype correlations were analyzed.

Results: Biallelic DUOX2 mutations were detected in 20 participants. All of them were born full term. All patients were treated with L-T4 when diagnosed with $\mathrm{CH}$; 9 of them stopped L-T4 eventually before 3 years old; and 2 were treated with a reduced dose of L-T4 (12.5 $\mu \mathrm{g}$ per day). The others were still treated with L-T4 at a dose of 37.5-87.5 $\mu \mathrm{g}$ per day. Of these 20 participants, 5 carried an R1110Q variant and 5 carried K530X variants. A total of 7 novel variants were discovered in our cohort. The variants carried in transient $\mathrm{CH}$ patients were located extracellularly and not near the functional domain.

Conclusions: Most $\mathrm{CH}$ patients with DUOX2 mutations were those with transient or subclinical $\mathrm{CH}$. The R1110Q, R885L, and K530X were the most common variants in our Chinese cohort. The R1110Q and K530X variants may play a founder effect in the transient $\mathrm{CH}$. The R885L variant may play a benign role in transient $\mathrm{CH}$. Intracellular variants or those near the functional domain may cause permanent $\mathrm{CH}$.
\end{abstract}

Keywords: Congenital hypothyroidism (CH); dual oxidase 2 (DUOX2); Chinese; phenotype genotype

Submitted Oct 10, 2020. Accepted for publication Dec 04, 2020.

doi: $10.21037 /$ atm-20-7165

View this article at: http://dx.doi.org/10.21037/atm-20-7165

\section{Introduction}

Early in the 1980s, the thyroid $\mathrm{H}_{2} \mathrm{O}_{2}$ generator was found in the apical plasma membrane of pig open follicles (1). In 1999, Leseney et al. found biochemical characterization of a $\mathrm{Ca} 2+/ \mathrm{NAD}(\mathrm{P}) \mathrm{H}$-dependent $\mathrm{H}_{2} \mathrm{O}_{2}$ generator in human thyroid tissue (2). The dual oxidase 2 (DUOX2) gene was firstly purified in 1999 and located on chromosome $15 \mathrm{q} 21.1$, consisting of 34 exons (3). In 2007, the mouse
DUOX2 mutation was reported to have occurred spontaneously at the Jackson Laboratory and was named "thyroid dyshormonogenesis" to signify the characteristic defect of thyroid hormone synthesis (4). This is currently the only known gene that causes transient congenital hypothyroidism $(\mathrm{CH})$, but its mechanism has not yet been clarified. The protein encoded by this gene is a glycoprotein and a member of the nicotinamide adenine dinucleotide 
phosphate (NADPH) oxidase family. The synthesis of thyroid hormone is catalyzed by a protein complex located at the apical membrane of thyroid follicular cells. This complex contains an iodide transporter, thyroperoxidase, and a peroxide generating system that includes this encoded protein and dual oxidase 1 (DUOX1) (5).

In 2002, Moreno et al. found the inactivated mutation of DUOX2 gene in $9 \mathrm{CH}$ patients (1 permanent and 8 transient) (6). After that, additional cases were reported with DUOX2 gene mutations (7), and they found that a missense mutation (p.R1110Q) may cause thyroid goiter. In China, Liu et al. found 2 novel missense mutations (p.R354W and p.A1206T) impaired $\mathrm{H}_{2} \mathrm{O}_{2}$ production and caused $\mathrm{CH}$ and goiter (8).

However, none of the above studies have clarified the pathogenesis of transient hypothyroidism, and the potential mechanism may not be discovered. Longterm outcome data are insufficient to determine further outcomes of transient $\mathrm{CH}$. Therefore, we have endeavored to spend years following up these patients and intend to explore the association between the DUOX2 genotype and phenotype in the treatment of patients with DUOX2 mutation hypothyroidism. We present the following article in accordance with the MDAR checklist (available at http:// dx.doi.org/10.21037/atm-20-7165).

\section{Methods}

\section{Participants}

A total of 61 patients who presented with low thyroxine (T4) and free thyroxine (FT4) levels, and thyroid stimulating hormone (TSH) levels $>10 \mathrm{mIU} / \mathrm{mL}$ detected by the national neonatal newborn screening program were recruited (9). Whole-exome sequencing was performed and 20 patients ( 7 males, 13 females) among them were found to harbor biallelic DUOX2 mutations. All patients were double checked in our hospital and thereafter treated with L-thyroxine (L-T4) at an initial dosage of $10-15 \mu \mathrm{g} / \mathrm{kg}$ per day (9). The L-T4 dosages were titrated at the suggested serum level of TSH $<3 \mathrm{mIU} / \mathrm{mL}$ (9). Transient $\mathrm{CH}(\mathrm{TCH})$ or permanent $\mathrm{CH}(\mathrm{PCH})$ classification of the patients was dependent on the need of L-T4 in maintaining euthyroidism. After withdrawal of therapy, serum TSH, $\mathrm{fT} 3$, and fT4 of all patients were followed once or twice a year until the present.

This study was approved by the ethics committee of Children's Hospital of Fudan University (No. 2015-183).
All participants consented to this research, as provided by their parents or guardians. The samples were collected according to the World Medical Association Declaration of Helsinki (as revised in 2013).

\section{Study methods}

\section{Statistics Analysis}

Continuous variables are expressed in mean \pm standard deviation (SD). Comparison between permanent and transient hypothyroidism was performed by unpaired t-test. $P$ values $<0.05$ were considered statistically significant. The statistical analysis was performed using R (v. 4.0.3, www.r-project.org)

\section{Whole-exome sequencing}

Frozen peripheral blood samples were sent to a service provider for whole-exome sequencing (WES) and disease related mutation analysis (Shanghai Gemple Biotechnology Co., Ltd., Shanghai, China). Total DNA was isolated using the UnigeneDx Blood DNA extraction Kit (Unigene Laboratories Inc., Boonton, NJ, USA), and DNA concentration was determined using the Qubit dsDNA HS assay kit (Life Technologies, Carlsbad, CA, USA). Exome sequencing libraries were prepared using the KAPA Hyper Prep Kit (KAPA Biosystems, Roche, Indianapolis, IN, USA), and enrichment was performed with the SeqCapEZ MedExome Kit (NimbleGen, Roche, Indianapolis, IN, USA) following the manufacturer's instructions. Briefly, genomic DNA was sheared to an average size of 180-300 bp using the Covaris M200 sonicator (Covaris, Inc., Woburn, MA, USA). About $300 \mathrm{ng}$ fragmented genomic DNA was used for library construction. The DNA libraries were then pooled as 4-plex or 6-plex for capturing using the SeqCapEZ MedExome probes. Libraries were sequenced with the Illumina HiSeq platform using $150 \mathrm{bp}$ paired-end sequencing.

\section{Bioinformatic analysis}

An average of $10 \mathrm{~Gb}$ raw data (Fastq) as input was generated for each sample by Illumina sequencers. Firstly, the paired-end reads were performed for quality control using FastQC version 0.11.5 (http:// www.bioinformatics.babraham.ac.uk/projects/fastqc). Secondly, Burrows-Wheeler Aligner (BWA) version 0.7 .15 (10) was used to align sequencing reads to the reference genome GRCh38. Sequence alignment/map (SAM) format files were generated by BWA. Thirdly, 
Table 1 Genes which are reported related with congenital hypothyroidism

\begin{tabular}{|c|c|c|c|}
\hline Genes & Location & Exons & Full name \\
\hline TSHR & $14 q 31$ & 12 & Thyroid stimulating hormone receptor \\
\hline TPO & $2 p 25$ & 19 & Thyroid peroxidase \\
\hline MCT8(SLC16A2) & Xq13 & 6 & Solute carrier family 16 (monocarboxylic acid transporters), member 2 \\
\hline PAX8 & $2 q 13$ & 12 & Paired box (PAX) family of transcription factors \\
\hline TSHB & $1 \mathrm{p} 13$ & 3 & Thyroid stimulating hormone, beta \\
\hline THRB & $3 p 24.2$ & 17 & Thyroid hormone receptor, beta \\
\hline DUOX2 & $15 q 15.3$ & 34 & Dual oxidase 2 \\
\hline FOXE1 & 9q22 & 1 & Forkhead box E1 \\
\hline PDE8B & $5 q 13.3$ & 26 & Phosphodiesterase 8B \\
\hline GNAS & $20 q 13.3$ & 16 & GNAS complex locus \\
\hline TTF2 & $1 \mathrm{p} 22$ & 25 & Transcription termination factor, RNA polymerase \\
\hline POU1F1 & $3 p 11$ & 6 & POU class 1 homeobox 1 \\
\hline GLIS3 & $9 p 24.2$ & 19 & GLIS family zinc finger 3 \\
\hline DEHAL1 (IYD) & $6 q 25.1$ & 7 & lodotyrosine deiodinase \\
\hline THRA & $17 q 11.2$ & 11 & Thyroid hormone receptor, alpha \\
\hline
\end{tabular}

the SAM format files were further processed to binary SAM (BAM) files using Samtools version 1.3.1 (11), then duplicates were removed using Picard version 2.5 (12). After these processes, variant calling was performed by GATK version 3.5 (13), and the Vcf file was generated. Finally, we used Annovar software to annotate the variants from the Variant Call Format (VCF) file and integrate information from multiple databases. The final variants could feed to the downstream advanced analysis pipeline.

\section{Variation filtering and validation}

Initially, we focused on variants in 30 candidate genes which have been implicated in $\mathrm{CH}$ or thyroid dysgenesis. This core gene list was determined by databases such as Online Mendelian Inheritance in Man (OMIM) and GeneReviews, as well as published literature, and is supplied in Table 1. Variants were analyzed following the basic criteria from American College of Medical Genetics (ACMG) guideline (14). Confirmation of variants identified by WES was carried out using standard Sanger sequencing using polymerase chain reaction. Polyphen-2 (http://genetics.bwh.harvard. edu/pph2/) and mutation taster (http://asia.ensembl.org/ index.html) tools were used for all novel variants to predict whether they were pathogenic mutations.

\section{Results}

In these 61 patients, we all carried out genetic test. Twenty of them were with DUOX2 variations. Six of them were TSHR variations, 2 of them were GNAS variations, 2 of them were DUOXA2 variations, 1 of them were NIS variation, 1 of them was TG variation, the others were negative. 


\section{Thyroxine level of participants with mutations in DUOX2}

$\mathrm{T} 4$ level was $3.03 \pm 1.49 \mu \mathrm{g} / \mathrm{dL}$ in $\mathrm{PCH}$ group versus $4.73 \pm 2.33 \mu \mathrm{g} / \mathrm{dL}$ in TCH group. FT4 level was $0.53 \pm 0.18 \mathrm{ng} / \mathrm{dL}$ in $\mathrm{PCH}$ group versus $0.67 \pm 0.27 \mathrm{ng} / \mathrm{dL}$ in TCH group. TSH level was $73.63 \pm 18.72 \mathrm{mIU} / \mathrm{mL}$ in PCH group versus $53.41 \pm 32.02 \mathrm{mIU} / \mathrm{mL}$ in TCH group. No significant difference was found in each above groups.

\section{Clinical course of participants with mutations in DUOX2}

In most participants, thyroid function was improved and the dose of L-T4 could be reduced by around 2-4 years of age, except for the siblings in cases 13 and 14. Some 10 of the 20 patients aged 3-7 years old were able to have their L-T4 dose gradually reduced and then eventually stopped altogether at the age of 2-3 years. After stopping L-T4, these patients still followed up in our clinic and the levels of thyroid hormone continued to be normal. Case 13 and 14 were siblings with same homozygous mutations of p.R1110Q, and both developed PCH. They were born in 2010 and 2013, respectively; their doses of L-T4 were $50 \mu \mathrm{g}$ per day at birth and are now $87.5 \mu \mathrm{g}$ per day to maintain normal levels of TSH, fT3, and fT4 and PCH. Case 9 was lost due to ceased contact. In the other participants, 2 (cases 18 and 19) have had their L-T4 doses reduced to $12.5 \mu \mathrm{g}$ and might try to stop L-T4 in the future follow-up. The participant known as case 4 has had their dose reduced to $25 \mu \mathrm{g}$ per day. Cases 1 and 7 have reduced theirs to $37.5 \mu \mathrm{g}$ per day. Case 10 and $20(n=2)$ are maintained $50 \mu$ g per day. All patients were assessed as physically and psychologically normal until recently. This phenomenon indicates that most patients with DUOX2 mutations have slightly subclinical hypothyroidism (Table 2). During puberty, none of the transient cases showed signs of hypothyroidism (elevation of TSH or reduction of fT4 level).

\section{Genotypes of patients with mutations in DUOX2}

All participants had biallelic DUOX2 variants (Table 2). All parents of the participants in this study are carriers of monoallelic DUOX2 mutations, and they did not have a history of hypothyroidism. Of these 20 patients, 5 carried an R1110Q variant and 5 carried K530X variants, which indicated that both variants might be the hot sites of DUOX2 in our Chinese CH cohort. A total of 7 novel variants were detected (Table 2). Prediction of the functional effects of the novel missense variants was made using polyphen-2 and mutation taster. Novel variants c.3363_3364delCA (p.D1121fsX48), c.C3956T (p.T1319I), c.C411A (p.D137E), c.T959C (p.L320P), c.3516_3531delGTCCAAGCTTCCCCAG, and c.3285_3286delTT were predicted to be disease causing by mutation taster and probably damaging by polyphen- 2 . Novel variant c.G1127T (p.R376L) was predicted as disease causing by mutation taster but benign by polyphen- 2 .

\section{Discussion}

As reported, the incidence of $\mathrm{CH}$ in China is about $1: 2,050$ (15), and the global incidence rate is about $1: 581-4,400$ (16-19). Most of the CH is sporadic, but it is also related to genetic factors. Currently known mutations include NKX2-1, NKX2-5, PAX8, TTF2, and thyrotropin receptor (TSHR) (20). Thyroid hormone abnormalities are associated with genetic defects involved in thyroid hormone synthesis. Pathogenic genes include DUOX2, thyroid peroxidase (TPO), solute carrier family 5 or sodium iodide symporter (SLC5A/NIS), thyroglobulin (TG), iodine tyrosine deiodinase (IYD), dual oxidase maturation factor 2 (DUOXA2), and solute carrier family 26 member 4 (SLC26A4) (20).

Reports on CH caused by the DUOX2 gene have been gradually increasing. Since 2014, after the application of next-generation sequencing (NGS) technology to clinical genetic diagnosis services, large-scale research has become more common. Increasing numbers of mutation sites have been discovered. We reviewed the majority of published research and listed the reported mutation sites correlated with the natural course of $\mathrm{CH}(5,6,21-34)$ (Table 3). All these papers analyzed the correlation between phenotype and genotype, as it is considered that either TCH or PCH might be determined by the different mutations. Our study found that patients with homozygous variants of R1110Q may have $\mathrm{PCH}$, and heterozygous variations may lead to $\mathrm{TCH}$, consistent with some previous findings. In the results of other research institutions in China, the K530X and R885L variants were found to be common in the Chinese population $(22,31,35)$, and these findings concur with our findings. In the majority of our cases, patients with R885L variants only had TCH, which indicated the R885L might be a benign variant. We also found 8 participants (case 2, $3,10,12,16,17,18$, and 20) with 7 novel variant sites that were predicted by software to be pathogenic. Most of these participants were TCH while cases 10,16 , and 20 were PCH. Cases 16 and 20 carried the same variant of A1206T, 
Table 2 Phenotypes and genotypes data of our cohort

\begin{tabular}{|c|c|c|c|c|c|c|c|c|c|}
\hline \multirow{2}{*}{ Case } & \multirow{2}{*}{ Sex } & \multirow{2}{*}{ Age } & \multirow{2}{*}{$\begin{array}{l}\mathrm{T} 4(\mu \mathrm{g} / \mathrm{dL}) \\
(4.5-15.4)\end{array}$} & \multirow{2}{*}{$\begin{array}{c}\text { TSH }(\mu \mathrm{lU} / \mathrm{mL}) \\
(0.25-7.31)\end{array}$} & \multirow{2}{*}{$\begin{array}{c}\text { FT4 (ng/dL) } \\
(0.5-2.3)\end{array}$} & \multirow{2}{*}{$\begin{array}{c}\text { Allele 1, } \\
\text { Amino acid }\end{array}$} & \multirow{2}{*}{$\begin{array}{c}\text { Allele 2, } \\
\text { Amino acid }\end{array}$} & \multirow{2}{*}{$\begin{array}{c}\text { Current treatment } \\
\text { Oral treatment of L-T4 }\end{array}$} & \multirow{2}{*}{ Clinical course } \\
\hline & & & & & & & & & \\
\hline 1 & $\mathrm{~F}$ & 5 & 4.33 & 37.5 & 0.77 & p.K530X & p.R1211H & $37.5 \mu \mathrm{g}$ per day & Permanent \\
\hline 2 & $M$ & 5 & 4.74 & 28.9 & 0.62 & p.R1110Q & p.D137E & Stopped & Transient \\
\hline 3 & $\mathrm{~F}$ & 5 & 2.65 & $>100$ & 0.38 & p.D1121fsX48 & p.R1110Q & Stopped & Transient \\
\hline 5 & $M$ & 7 & 9.32 & 13.01 & 1.06 & p.R885L & p.R885L & Stopped & Transient \\
\hline 6 & $M$ & 6 & 4.84 & 36.72 & 0.54 & p.K530X & p.S199fs & Stopped & Transient \\
\hline 7 & $\mathrm{~F}$ & 10 & 2.43 & 53.4 & 0.43 & p.R683L & p.R885Q & $37.5 \mu \mathrm{g}$ per day & Permanent \\
\hline 8 & $\mathrm{~F}$ & 4 & 7.87 & 72.51 & 0.98 & p.L1343F & p.R683L & Stopped & Transient \\
\hline 11 & $M$ & 8 & 3.94 & 100 & 0.49 & p.K530X & p.K530X & Stopped & Transient \\
\hline 12 & $\mathrm{~F}$ & 4 & 5.47 & 27.83 & 0.62 & p.R885L & p.Q570X & Stopped & Transient \\
\hline 13 & $M$ & 10 & 1.33 & 78.2 & 0.53 & p.R1110Q & p.R1110Q & $87.5 \mu \mathrm{g}$ per day & Permanent \\
\hline 14 & $\mathrm{~F}$ & 7 & 1.45 & 89.3 & 0.34 & p.R1110Q & p.R1110Q & $87.5 \mu \mathrm{g}$ per day & Permanent \\
\hline 15 & $\mathrm{~F}$ & 4 & 1.98 & 100 & 0.53 & p.R885L & p.K530X & Stopped & Transient \\
\hline 16 & $\mathrm{~F}$ & 6 & 3.62 & 38.3 & 1.09 & p.A1206T & p.R376L & Stopped & Transient \\
\hline 17 & $M$ & 5 & 2.87 & 63.4 & 0.42 & p.T1319l & p.K530X & Stopped & Transient \\
\hline 18 & $\mathrm{~F}$ & 2 & 4.44 & 81.65 & 0.65 & p.R1110Q & p.Gly1173SerfsX14 & $12.5 \mu \mathrm{g}$ per day & Mild permanent \\
\hline
\end{tabular}

No data: patients lost to follow-up.

which hinted that the A1206T variant might be the cause of $\mathrm{PCH}$.

Through the changes in amino acids at these sites, as well as systematic reviews of other literature, we have some hypotheses for the pathogeneses of PCH and TCH. The possible mechanism by which DUOX2 mutations cause transient $\mathrm{CH}$ is as follows. A possible reason was raised in 2016 by Maruo et al., who investigated the prognosis of patients with $\mathrm{CH}$ due to DUOX2 mutations and raised the hypothesis that DUOX1 compensated the DUOX2 mutation in thyroid cells which produce $\mathrm{H}_{2} \mathrm{O}_{2}$ for tissue and coupling of tyrosine in the infancy and adult period. The expression level of DUOX1 is one-fifth of DUOX2. Even though DUOX2 enzyme activity is lost, DUOX1 maintains low levels of $\mathrm{H}_{2} \mathrm{O}_{2}$ throughout life. In the neonatal period, the demand for thyroid hormone
$(10-15 \mathrm{mcg} / \mathrm{kg})$ is $5-7$ times higher than that of adults $(2 \mathrm{mcg} / \mathrm{kg}$ ), then, the demand for thyroid hormones in infancy is gradually reduced. In the neonatal and infancy periods, the supply of $\mathrm{H}_{2} \mathrm{O}_{2}$ using DUOX1 alone may be insufficient, so individuals with DUOX2 deficiency are prone to signs of $\mathrm{CH}$. As thyroid hormone requirements decrease during development, DUOX1 produces sufficient $\mathrm{H}_{2} \mathrm{O}_{2}$ to maintain thyroid hormone synthesis, regardless of DUOX2 mutations (36). This hypothesis may explain the occurrence of $\mathrm{TCH}$, but it cannot explain the phenomenon of PCH.

In our study, variants of $\mathrm{PCH}$ patients were almost near the functional domain of DUOX2 (Figure 1), which may affect the normal expression of the gene. This might be a possible mechanism of $\mathrm{PCH}$. Stop codon mutations are considered pathogenic in ACMG guidelines. However, 
Table 3 Reported natural course of congenital hypothyroidism in previous researches

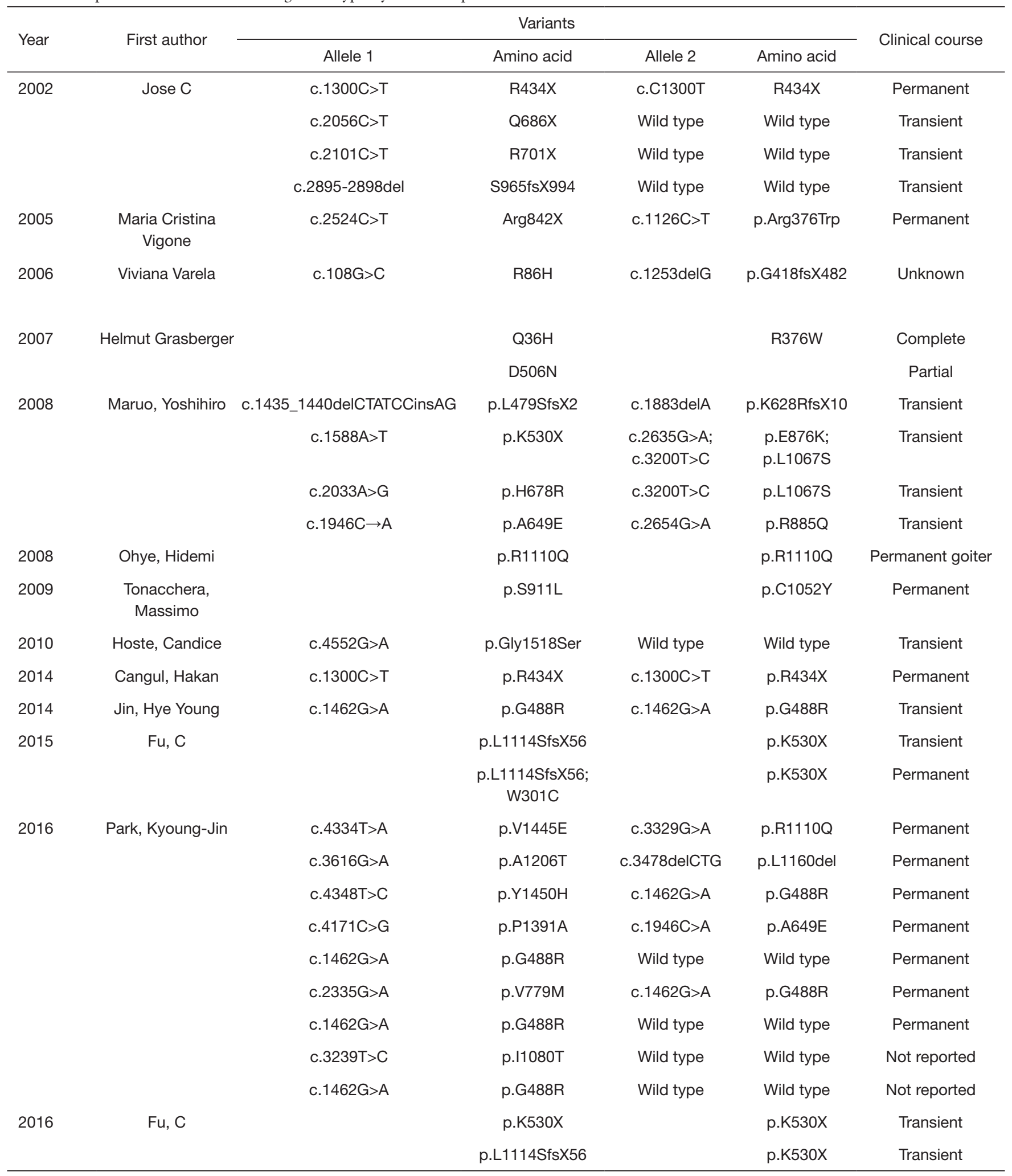

Table 3 (continued) 
Table 3 (continued)

\begin{tabular}{|c|c|c|c|c|c|c|}
\hline Year & First author & \multicolumn{4}{|c|}{ Variants } & Clinical course \\
\hline \multirow[t]{6}{*}{2016} & Tan & & p.K530X & & p.K530X & Transient \\
\hline & & & p.K530X & & p.K530X & Transient \\
\hline & & & p.K530X & & p.K530X & Transient \\
\hline & & & p.K530X & & p.Q202RfsX93 & Transient \\
\hline & & c.647-656del10ins 15 & & & p.K530X & $\begin{array}{l}\text { Mild permanent/ } \\
\text { transient }\end{array}$ \\
\hline & & & p.K530X & & p.K530X & Transient \\
\hline 2016 & & c. $2033 A>G$ & p.H678R & rs145061993 & p.V779M & Permanent \\
\hline 2017 & Aycan, Zehra & c. $1300 \mathrm{C}>\mathrm{T}$ & p.R434X & c. $1300 \mathrm{C}>\mathrm{T}$ & p.R434X & Permanent \\
\hline \multirow[t]{2}{*}{2018} & Liu & & p.R354W & & & Transient \\
\hline & & & p.A1206T & & & Transient \\
\hline
\end{tabular}

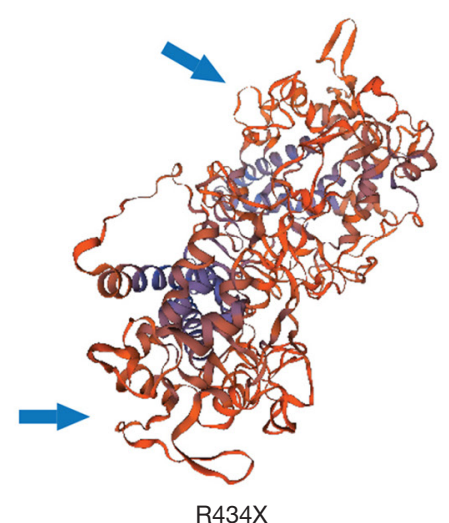

$\mathrm{R} 434 \mathrm{X}$

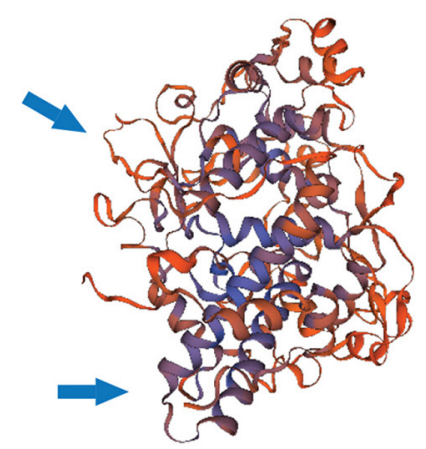

Wild type

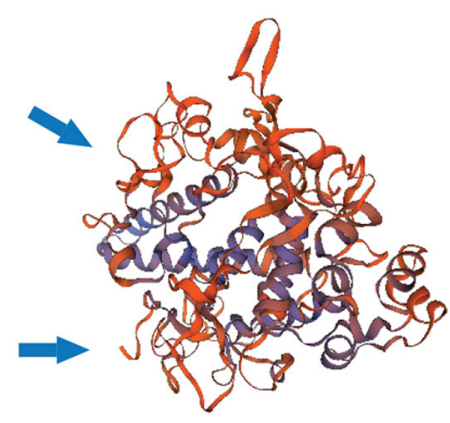

K530X

Figure 1 Predicted structures of different DUOX2 gene variants. The structure of the DUOX2 indicated by the arrow in the figure is different. The structure of R434X is relatively loose and partially missing. The protein structure change caused by K530X is mild. DUOX2, dual oxidase 2 .

most patients with a $\mathrm{K} 530 \mathrm{X}$ variant were $\mathrm{TCH}$ while most patients with an $\mathrm{R} 434 \mathrm{X}$ variant were $\mathrm{PCH}$. We used software (https://www.swissmodel.expasy.org/interactive) to predict protein structure, and found the predicted protein structure of K530X was more similar and relatively intact compared with the wild type, but the predicted protein structure of $\mathrm{R} 434 \mathrm{X}$ was more variable (Figure 2). The difference of protein structure could alter the activity of the DUOX2 protein, which may be the cause of differences in their natural course of disease.

This study suggests that our patients with congenital hypothyroidism caused by mutations in the DUOX2 gene 


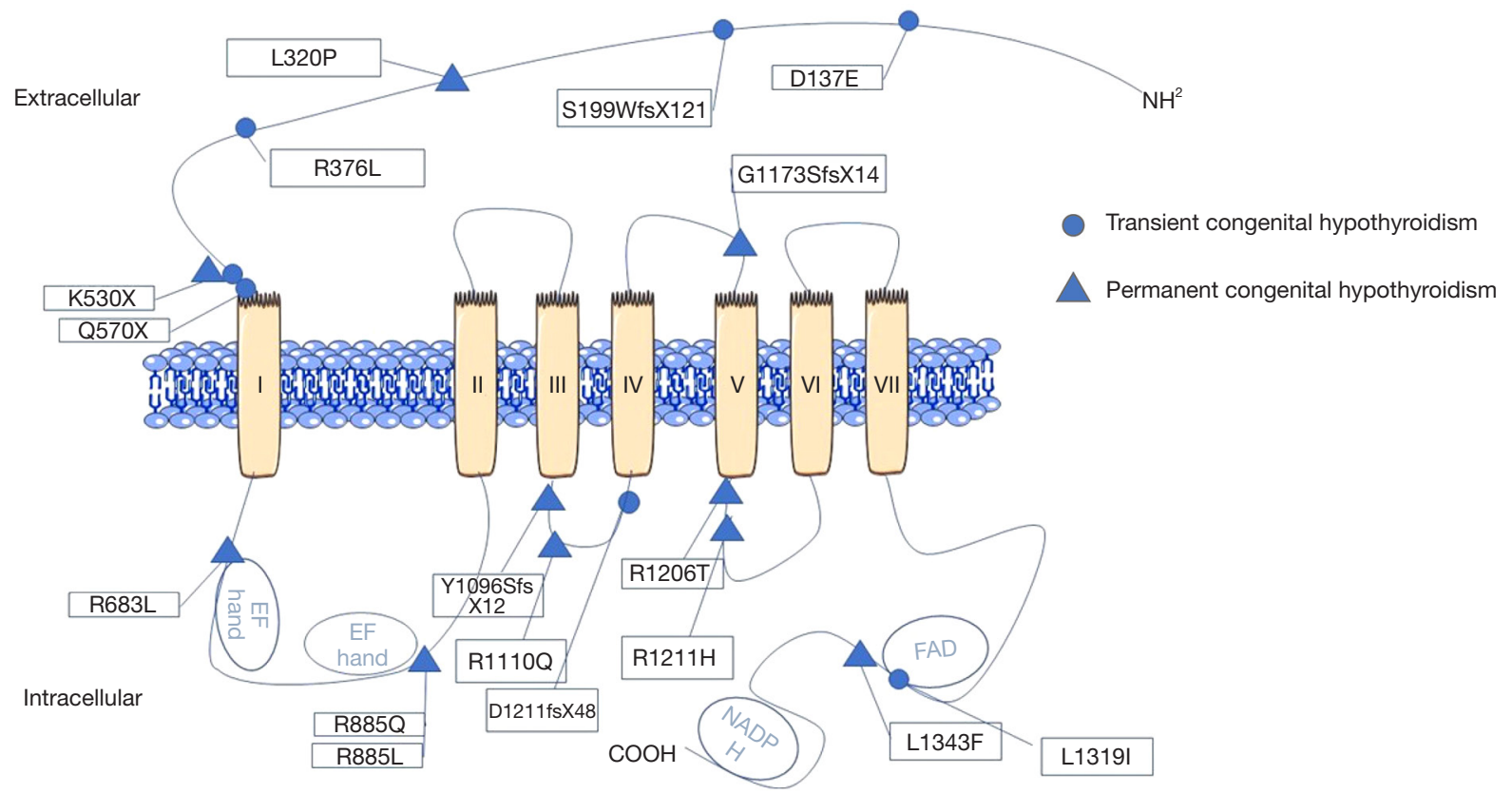

Figure 2 All variants detected in our cohort and their position in the functional domain of DUOX2 gene. DUOX2, dual oxidase 2 .

are partially transient hypothyroidism. The important findings can be translated into reference materials for clinicians diagnosis and treatment behaviors. And there is a big expectation that the patients don't need to take thyroxine for life, so that disease burden is decreased, and gain increasing compliance.

However, there are still limitations in our study. Thyroid globulin levels were not measured in our cohort. We were also unable to verify the functions of novel variants. Therefore, functional tests of novel DUOX2 variants such as constructing animal models or iPSC cells should be carried out in the future.

\section{Acknowledgments}

Funding: This study was supported by Fund EK112520180204 from Children's Hospital of Fudan University.

\section{Footnote}

Reporting Checklist: The authors have completed the MDAR checklist. Available at http://dx.doi.org/10.21037/atm-207165

Data Sharing Statement: Available at http://dx.doi. org/10.21037/atm-20-7165

Conflicts of Interest: All authors have completed the ICMJE uniform disclosure form (available at http://dx.doi. org/10.21037/atm-20-7165). The authors have no conflicts of interest to declare.

Ethical Statement: The authors are accountable for all aspects of the work in ensuring that questions related to the accuracy or integrity of any part of the work are appropriately investigated and resolved. The study was conducted in accordance with the Declaration of Helsinki (as revised in 2013). The study was approved by ethics board of Children's Hospital of Fudan University (No. 2015-183 the registration number of ethics board) and informed consent was taken from all individual participants.

Open Access Statement: This is an Open Access article distributed in accordance with the Creative Commons Attribution-NonCommercial-NoDerivs 4.0 International License (CC BY-NC-ND 4.0), which permits the noncommercial replication and distribution of the article with the strict proviso that no changes or edits are made and the original work is properly cited (including links to both the formal publication through the relevant DOI and the license). 
See: https://creativecommons.org/licenses/by-nc-nd/4.0/.

\section{References}

1. Björkman $\mathrm{U}$, Ekholm R. Generation of $\mathrm{H} 2 \mathrm{O} 2$ in isolated porcine thyroid follicles. Endocrinology 1984;115:392-8.

2. Leseney AM, Dème D, Legué $\mathrm{O}$, et al. Biochemical characterization of a $\mathrm{Ca} 2+/ \mathrm{NAD}(\mathrm{P}) \mathrm{H}$-dependent $\mathrm{H} 2 \mathrm{O} 2$ generator in human thyroid tissue. Biochimie 1999;81:373-80.

3. Dupuy C, Ohayon R, Valent A, et al. Purification of a novel flavoprotein involved in the thyroid NADPH oxidase Cloning of the porcine and human cdnas. J Biol Chem 1999;274:37265-9.

4. Johnson KR, Marden CC, Ward-Bailey P, et al. Congenital hypothyroidism, dwarfism, and hearing impairment caused by a missense mutation in the mouse dual oxidase 2 gene, Duox2. Mol Endocrinol 2007;21:1593-602.

5. Aycan Z, Cangul H, Muzza M, et al. Digenic DUOX1 and DUOX2 mutations in cases with congenital hypothyroidism. J Clin Endocrinol Metab 2017;102:3085-90.

6. Moreno JC, Bikker H, Kempers MJ, et al. Inactivating mutations in the gene for thyroid oxidase 2 (THOX2) and congenital hypothyroidism. N Engl J Med 2002;347:95-102.

7. Satoh M, Aso K, Ogikubo S, et al. Genetic analysis in children with transient thyroid dysfunction or subclinical hypothyroidism detected on neonatal screening. Clin Pediatr Endocrinol 2009;18:95-100.

8. Liu S, Zhang W, Zhang L, et al. Genetic and functional analysis of two missense DUOX2 mutations in congenital hypothyroidism and goiter. Oncotarget 2016;9:4366.

9. Group of Endocrinology and Inborn Metabolic Diseases Cps, Chinese Medical association. Consensus of diagnosis and treatment of congenital hypothyroidism. Chinese Journal of Pediatrics 2011;49:421-4.

10. Li H, Durbin R. Fast and accurate short read alignment with Burrows-Wheeler transform. Bioinformatics 2009;25:1754-60.

11. Li H, Handsaker B, Wysoker A, et al. The Sequence Alignment/Map format and SAMtools. Bioinformatics 2009;25:2078-9.

12. Picard. Available online: http://broadinstitute.github.io/ picard/

13. McKenna A, Hanna M, Banks E, et al. The Genome Analysis Toolkit: a MapReduce framework for analyzing next-generation DNA sequencing data. Genome Res
2010;20:1297-303.

14. Richards S, Aziz N, Bale S, et al. Standards and guidelines for the interpretation of sequence variants: a joint consensus recommendation of the American College of Medical Genetics and Genomics and the Association for Molecular Pathology. Genet Med 2015;17:405.

15. Gu X, Wang Z, Ye J, et al. Newborn screening in China: phenylketonuria, congenital hypothyroidism and expanded screening. Ann Acad Med Singapore 2008;37:107-4.

16. Roberts H, Moore C, Fernhoff P, et al. Population study of congenital hypothyroidism and associated birth defects, Atlanta, 1979-1992. Am J Med Genet 1997;71:29-32.

17. Kurinczuk J, Bower C, Lewis B, et al. Congenital hypothyroidism in Western Australia 1981-1998. J Paediatr Child Health 2002;38:187-91.

18. Chang IJ, He M, Lam CT. Congenital disorders of glycosylation. Ann Transl Med 2018;6:477.

19. Hinojosa-Trejo MA, Vela-Amieva M, Ibarra-González I, et al. Congenital hypothyroidism birth prevalence. Acta Pediátrica de México 2019;39:5-13.

20. Szinnai G. Clinical genetics of congenital hypothyroidism. Endocr Dev 2014;26:60-78.

21. Cangul H, Aycan Z, Kendall M, et al. A truncating DUOX2 mutation (R434X) causes severe congenital hypothyroidism. J Pediatr Endocrinol Metab 2014;27:323-7.

22. Fu C, Luo S, Zhang S, et al. Next-generation sequencing analysis of DUOX2 in 192 Chinese subclinical congenital hypothyroidism $(\mathrm{SCH})$ and $\mathrm{CH}$ patients. Clin Chim Acta 2016;458:30-4.

23. Fu C, Zhang S, Su J, et al. Mutation screening of DUOX2 in Chinese patients with congenital hypothyroidism. J Endocrinol Invest 2015;38:1219-24.

24. Grasberger H, De Deken X, Miot F, et al. Missense mutations of dual oxidase 2 (DUOX2) implicated in congenital hypothyroidism have impaired trafficking in cells reconstituted with DUOX2 maturation factor. Mol Endocrinol 2007;21:1408-21.

25. Hoste C, Rigutto S, Van Vliet G, et al. Compound heterozygosity for a novel hemizygous missense mutation and a partial deletion affecting the catalytic core of the $\mathrm{H} 2 \mathrm{O} 2$-generating enzyme DUOX2 associated with transient congenital hypothyroidism. Hum Mutat 2010;31:E1304-19.

26. Jin HY, Heo S-H, Kim Y-M, et al. High frequency of DUOX2 mutations in transient or permanent congenital hypothyroidism with eutopic thyroid glands. Horm Res Paediatr 2014;82:252-60. 
27. Maruo Y, Takahashi H, Soeda I, et al. Transient congenital hypothyroidism caused by biallelic mutations of the dual oxidase 2 gene in Japanese patients detected by a neonatal screening program. J Clin Endocrinol Metab 2008;93:4261-7.

28. Ohye H, Fukata S, Hishinuma A, et al. A novel homozygous missense mutation of the dual oxidase 2 (DUOX2) gene in an adult patient with large goiter. Thyroid 2008;18:561-6.

29. Park KJ, Park HK, Kim YJ, et al. DUOX2 mutations are frequently associated with congenital hypothyroidism in the Korean population. Ann Lab Med 2016;36:145-53.

30. Rostampour N, Tajaddini M, Hashemipour M, et al. The Mutation of Dual Oxidase 2 (DUOX2) Gene among Patients with Permanent and Transient Congenital Hypothyroidism. Pak J Med Sci 2012;28:287-92.

31. Tan M, Huang Y, Jiang X, et al. The Prevalence, Clinical, and Molecular Characteristics of Congenital Hypothyroidism Caused by DUOX2 Mutations: A Population-Based Cohort Study in Guangzhou. Horm Metab Res 2016;48:581-8.

32. Tonacchera M, De Marco G, Agretti P, et al. Identification and functional studies of two new dual-oxidase 2 (DUOX2) mutations in a child with congenital hypothyroidism and a eutopic normal-size thyroid gland. J Clin Endocrinol Metab 2009;94:4309-14.

33. Varela V, Rivolta CM, Esperante SA, et al. Three mutations (p. Q36H, p. G418fsX482, and g. IVS19-2A> C) in the dual oxidase 2 gene responsible for congenital goiter and iodide organification defect. Clin Chem 2006;52:182-91.

34. Vigone MC, Fugazzola L, Zamproni I, et al. Persistent mild hypothyroidism associated with novel sequence variants of the DUOX2 gene in two siblings. Hum Mutat 2005;26:395.

35. Jiang $\mathrm{H}, \mathrm{Wu} \mathrm{J}, \mathrm{Ke} \mathrm{S}$, et al. High prevalence of DUOX2 gene mutations among children with congenital hypothyroidism in central China. Eur J Med Genet 2016;59:526-31.

36. Maruo Y, Nagasaki K, Matsui K, et al. Natural course of congenital hypothyroidism by dual oxidase 2 mutations from the neonatal period through puberty. Eur J Endocrinol 2016;174:453-63.

(English Language Editor: J. Jones)
Cite this article as: Zheng Z, Yang L, Sun C, Wu J, Luo F, Zhou W, Lu W. Genotype and phenotype correlation in a cohort of Chinese congenital hypothyroidism patients with DUOX2 mutations. Ann Transl Med 2020;8(24):1649. doi: 10.21037/atm-20-7165 